\title{
Model Parameter Evaluation and Improvement for Real-Time Flood Inundation Mapping Using HAND Model: Iowa Case Study
}

\author{
Zhouyayan $\mathrm{Li}^{\mathrm{a}, \mathrm{b}^{*}}$, Jerry Mount ${ }^{\mathrm{b}}$, Ibrahim Demir ${ }^{\mathrm{a}, \mathrm{b}}$ \\ ${ }^{a}$ Department of Civil and Environmental Engineering, University of Iowa, Iowa City, Iowa, USA \\ ${ }^{b}$ IIHR Hydroscience and Engineering, University of Iowa, Iowa City, Iowa, USA \\ *Corresponding Author, Email: zhouyayan-li@uiowa.edu
}

This manuscript is an EarthArXiv preprint and has been submitted for possible publication in a peer-reviewed journal. Please note that this has not been peer-reviewed before and is currently undergoing peer review for the first time. Subsequent versions of this manuscript may have slightly different content. If accepted, the final version of this manuscript will be available via the 'Peer-reviewed publication DOI' link on this webpage. Please feel free to contact the authors; we welcome feedback. 


\title{
Model Parameter Evaluation and Improvement for Real-Time Flood Inundation Mapping Using HAND Model: Iowa Case Study
}

\begin{abstract}
In this study, the performance of Height Above Nearest Drainage (HAND) was evaluated in Linn, Jones, Johnson, Cedar, and Muscatine counties in the State of Iowa. The impacts of three model parameters (drainage threshold, water depth, resolution of data) were studied. The effectiveness of improving approaches_-variable water depths, community-level analysis, and inner zone was explored. The model performance was compared against flood hazard maps of 100- and 500-year flooding events generated by the Iowa Flood Center. Results showed the Hit Rate, Proportion Correct and Kappa Value reached 0.80 (0.79 for 500-year event), 0.93, and 0.69 ( 0.70 for 500 -year event) respectively, even when no improving approach was involved. The approaches helped Hit Rate improve to 0.88 for both flooding events, and Mixed Index increase by $5.83 \%$ (100-year event) and $5.77 \%$ (500-year event). The study presented how to improve the accuracy of HAND model in a simple and practical way.
\end{abstract}

\section{Keywords}

flood inundation mapping; Height Above the Nearest Drainage (HAND); model improvement; real-time inundation mapping

\section{Introduction}

Flood is one of the most devastating natural events that happen both in rural areas and urban regions (Hlodversdottir et al., 2015; Morris et al., 2016; Short Gianotti et al., 2018; Zhou et al., 2019) causing colossal life, and monetary losses every year (Arrighi et al., 2013; Sayama et al., 2015). Except for natural causes that lead to periodical flooding, climate change and urbanization are among the most influential factors that could intensify extreme flooding events in some regions (Huong and Pathirana, 2011; Mahmoud and Gan, 2018; Yazdanfar and Sharma, 2015). There is a trend for flooding events to happen even more frequently in the future since the need for impermeable pavements increases as more people tend to live in cities, and more extreme rainfall could appear because of the climate change (Hammond et al., 2015).

Humans have a long history of fighting against floods (Bukhari, 2016; Cœur, 2017; Yan, 2019), and numerical models and methods are playing an increasingly essential role in flood predictions 
with the development of advanced computing capabilities. Hydrodynamic and hydrological models, empirical methods, and simplified data-driven models are widely accepted for hydrological modeling, predictions and facilitates collaboration between data and geoscientists (Ebert-Uphoff et al., 2017). Among these methods, the simplified ones are receiving an increasing focus since they have significantly fewer data and computing needs, meanwhile, they are comparably robust and accurate (Teng et al., 2017). Unlike hydrodynamic models, simplified models do not focus on simulating the movement of water. Also, they do not divide study regions into small grids and apply equations of physics to these grids. Thus, the simplified models will not need boundary conditions, initial conditions, and the like to get started (Teng et al., 2017). In addition, unlike empirical methods that depend heavily on data acquisition and processing techniques, and the similarities between historical scenarios and the current scenario (Teng et al., 2017), results from simplified models could be more independent and robust. Some representatives of simplified models are Rapid Flood Spreading Method (RFSM) (Lhomme et al., 2008), Teng-Vaze-Dutta (TVD) (Teng et al., 2015), and Height Above the Nearest Drainage (HAND) (Rennó et al., 2008). The flood hazard map (FHM) that communicates flood information (inundation depths, extents) is a useful tool to reduce losses and support social developments (Kreibich et al., 2017, 2005; Mahmood, 2018). FHMs are vital to the society in the following aspects (Luke et al., 2018; Mahmood, 2018): providing essential information for long term flood risk management and response; helping in decision making (Carson et al., 2018) for both stakeholders and households; assisting in making effective land-use decisions, and being a useful tool for insurance professionals and lenders to calculate the premium of houses or businesses based on the risk level.

Like many other natural hazards in the world, a great number of regions and populations tend to be affected during a single flooding event. Therefore, an increasing effort has been put into large-scale flood inundation modeling as our understanding of hydrological process and computation capacity improve. Flood inundation maps are critical resource for mitigating damages from flooding and integrated to collaborative decision-making process (Sermet et al., 2020; Xu et al., 2020) and next generation communication applications using virtual reality (Sermet and Demir, 2019a). We have witnessed various recent advancements in this field. Gutenson et al. (2017) proposed a detailed workflow for generating runoff data for global flood inundation maps and carried out a case study for the flooding event caused by Typhoon Lionrock that hit North Korea in 2016. Tam et al. (2019) presented an evaluation study in Kelantan River Basin, Malaysia, to demonstrate the ability of four high spatial-temporal resolution satellite rainfall products to support rapid flood forecasting in terms of discharge and flood map simulation. Sanders and Schubert (2019) presented the Parallel Raster Inundation Model that is able to solve the shallow-water equations in a parallel and upscaling way that is more efficiently. As the researchers stated, the model enables relatively fast execution in large-scale hydraulic simulation, including subcritical, supercritical, transcritical flows, and compound flooding. 
In addition, obtaining FHMs and other hydrological information in a real-time manner is of great importance to next-generation decision making and hydrological modeling. We have witnessed efforts being put into real-time flood forecasting using machine learning (Sit and Demir, 2019; Xiang et al., 2020) and community-centric applications. Loi et al. (2019) proposed a real-time flood forecasting system that integrates SWAT, HEC-RAS, weather station network, and stream gauges. The system was tested in Vu Gia - Thu Bon river basin, Vietnam, and results showed good statistical correlation for calibration and validation periods. Yildirim and Demir (2019) presented a web-based framework for HAZUS-MH flood loss estimation, which provided a userfriendly platform for flood loss analysis and visualization. Haynes et al. (2018) presented a novel real-time Mobile Augmented Reality app that combined building models, flood visualization, and WeSenselt Citizen Water Observatory platform for the purpose of complementing existing flood risk management tools. Sermet and Demir (2019b) introduced a group of informationcentric ontologies that showed how flood domain knowledge can be integrated into expert systems and easily accessed with natural language queries on multiple platforms and devices. Sermet and Demir (2018) introduced an intelligent system that facilitates hydro-information collecting and analyzing, and communication through web-based information platforms and smart assistants. Recent developments in web and mobile technologies allow high-end capabilities on client-side systems in optimized network representation (Demir and Szczepanek, 2017), distributed volunteer computing for hydrological modeling (Agliamzanov et al., 2020), watershed delineation applications (Sit et al. 2019), stage measurements at ungauged sites (Sermet et al. 2019), and crowdsourced data exploration (Sit et al. 2019).

Being less computationally expensive, robust, and accurate, simplified models like HAND are favorable for creating real-time and/or large-scale FHMs and especially suitable for online applications. HAND was first introduced by Rennó et al. (2008) as a normalized digital elevation model that reflects the local soil water conditions, used for terrain classification (Nobre et al., 2011; Rennó et al., 2008). With its ability to reflect drainage potential, HAND was quickly adopted as a simplified hydrological model for flood inundation mapping. de Lollo et al. (2019) combined land use information and HAND to obtain quick and low-cost predictions of flood risks for Brazilian urban areas. Speckhann et al. (2018) presented a flood hazard mapping methodology by combining flow frequency analysis with HAND to generate the 2011 flood extent maps in the Itajai River basin, Brazil. Jafarzadegan and Merwade (2019) proposed a statistical approach that creates probabilistic floodplain maps using the HAND model. Their method proved to be able to reduce overestimation and underestimation. Godbout et al. (2019) proposed an approach to adjust the initial slope to improve the performance of the HAND model in reaches with extreme slopes. In addition to studies focusing on the methodology improvements, various comparisons between the HAND and other hydrological models exist in literature. For example, McGrath et al. (2018) presented a comparison among three non-physicsbased simplified flood models. The results showed HAND the best predictor for inundation 
extents among those three models. Afshari et al. (2018) carried out a comparison among HAND, AutoRoute, HEC-RAS 2D in Cedar River watershed, and part of the Black Warrior River. The results showed the modeling outcomes from HAND were comparable to those from other hydrological models and reference maps.

HAND is one of the most promising ones among all simplified models for large-scale flood inundation modeling in real-time applications. HAND model is adopted as the core technique of National Flood Interoperability Experiment (NFIE) (Maidment, 2017), which aims at simulating flood depth and extents at the continental scale using streamflow forecasts from National Water Model (NWM) (https://water.noaa.gov/about/nwm). Liu et al. (2016) proposed a cyberGIS approach to generate national-scale HAND maps at $10 \mathrm{~m}$ resolution. Two years later, they presented a scalable computation framework that couples HAND with NWM to generate near real-time inundation forecasts for Conterminous United States. The computational feasibility was tested on 331 HUC6 units and achieved a turnaround time of 1.5 days on ROGER supercomputer. After that, an additional $2.5 \mathrm{~h}$ and 45 minutes were taken for hydraulic property computing, storing, and 15 hourly inundation data and maps generating (Liu et al., 2018).

Researchers have been focusing on improving the performance of flood predictions based on the HAND model since it was introduced. Most studies in literature tried to achieve better performance by involving other data sources or methodology modifications. However, the point of the simplified models is all about keeping the workflow simple and easy to compute and implement, and about being able to generate robust results with minimum data requirements. Thus, in this study, our purpose is to figure out how the HAND's performance is affected by model parameters, and how we could make the most of the existing data and workflow to yield a better prediction. Although it is clear that HAND performance is affected by a limited number of parameters it requires, the literature is limited on comprehensive analysis showing how modeling results are influenced by its parameters. In this study, we demonstrated that HAND a useful tool for real-time flood inundation mapping, and presented a detailed analysis of the influences of all its parameters, and we also brought up some easy-to-implement tips with which we could further improve HAND performance. Although the approaches for improvement were tested in the Iowa case study, they can be applied anywhere to improve performance of the HAND model.

\section{Material and Methods}

\subsection{Real-Time HAND Mapping System}

We generated the flood inundation maps using a real-time implementation of the HAND model running entirely on client-side web systems (UIHILab, 2020). This system does not require any server-side GIS or database processing and allows users to set study scope and modify parameters when generating an inundation map on the web. Compared to many hydrodynamic or 
hydrological models that may take hours or days to finish a single run, this real-time inundation mapping system is capable of generating a flood extents map from scratch within a few minutes on demand. The flood extent maps are shown through image files, while users can export the results to raster files for further analyses. The system integrates reference flood map layers from the Iowa Flood Information System (IFIS) that communicates flood forecasts, warnings, and other related information to communities (Demir et al., 2018; Weber et al., 2018). Figure 1 shows the parameter selection and definition interface of the system. Five different grid sizes for HAND model $-1 \mathrm{~m}, 5 \mathrm{~m}, 10 \mathrm{~m}, 25 \mathrm{~m}$, and $50 \mathrm{~m}$, are available in the Resolution box for users to choose from. After choosing the resolution, users need to define the size of the region. The system is able to generate regions with the side length varying from one thousand all the way up to five thousand grids of the designated resolution. Then, users could choose Bare Earth or Elevation with Buildings options as the elevation data for HAND generation based on their own needs. Drainage Area (drainage threshold as described in this paper) and HAND (water depth as described in the paper) values accept user-defined integer or float inputs.

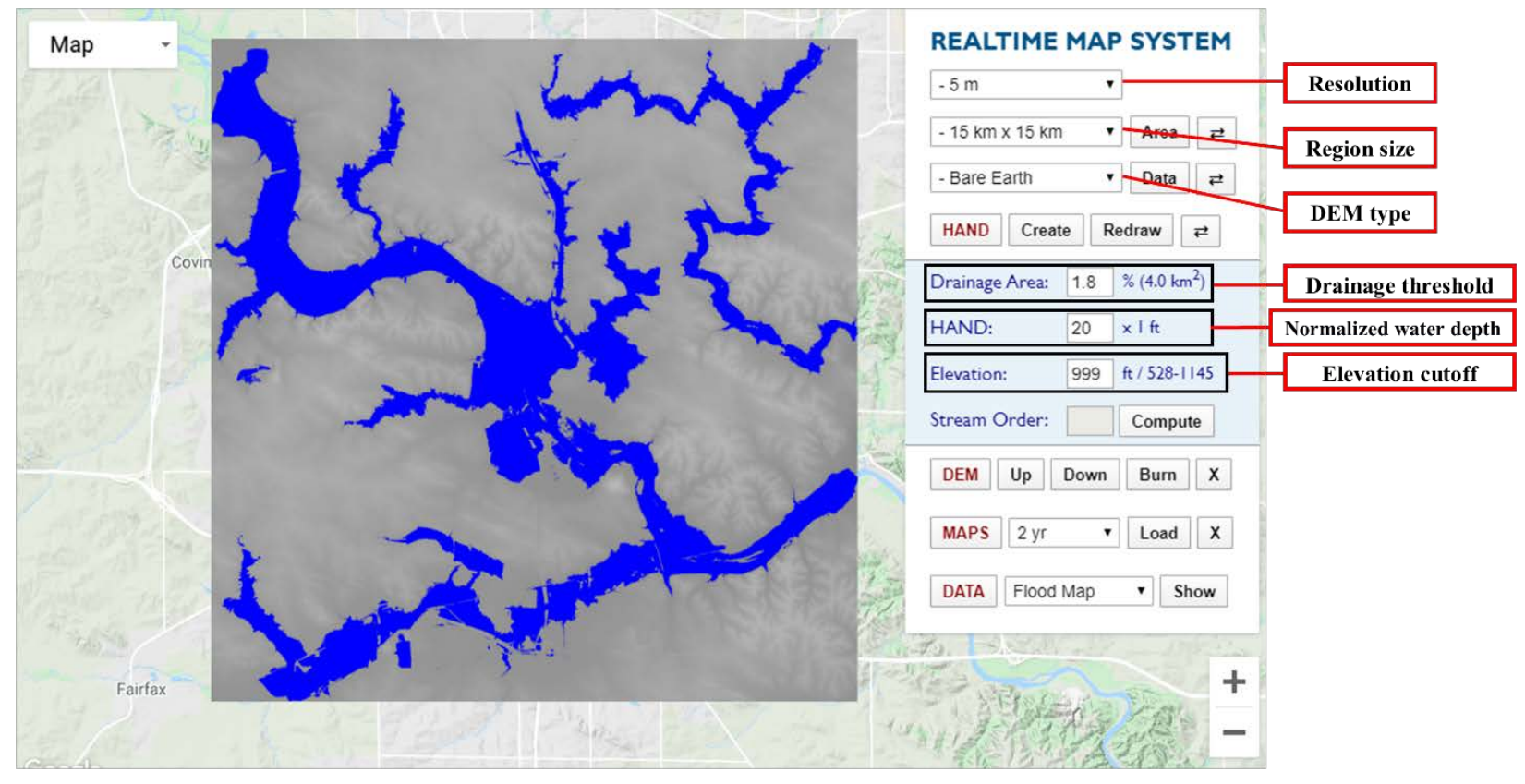

Figure 1 . The interface of the real-time map system developed by the UIHILab at the University of Iowa

Five counties in the southeast part of Iowa — Linn, Jones, Johnson, Cedar, and Muscatine, are selected as the study region for analysis. The five-county region covers about 7,650 $\mathrm{km}^{2}$ with the dominant land use of Cultivated Crops and the second dominant of Pasture/Hay. Water areas in the region is about $54 \mathrm{~km}^{2}$ in total. Figure 2 shows the scope of the five counties. 


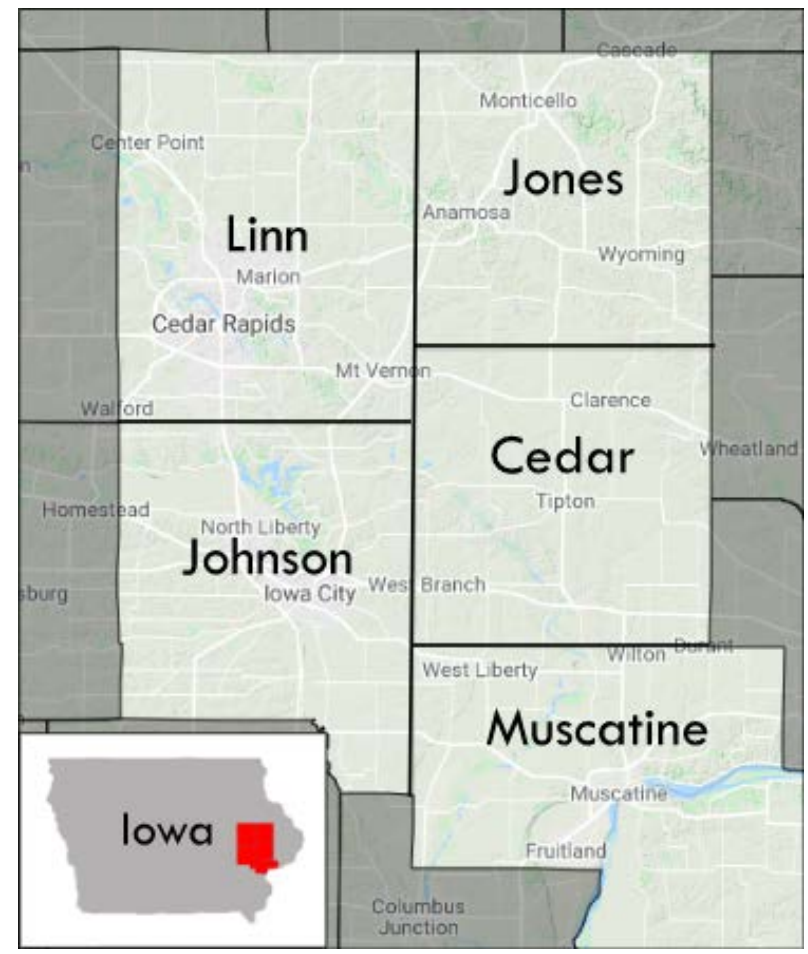

Figure 2. The regional scope of the case study and its location in the State of Iowa

\subsection{Data Processing and Integration}

Digital Elevation Model (DEM) data of the study region are integrated into Real-time Mapping System and can be accessed through web requests. We utilized the floodplain mapping products generated at the Iowa Flood Center (IFC) as reference maps. These maps are made available from the previous works at IFC, where the detailed floodplain maps are created with HECGeoRAS using LiDAR data of 1-m resolution (Gilles et al., 2012). Floodplain maps are generated in correspondence with flood events with 2-, 5-, 10-, 25-, 50-, 100-, 200-, and 500-year return period that cover the majority of the State of Iowa. Inundation maps used as references are hosted on the Iowa Flood Information System at the IFC (http://ifis.iowafloodcenter.org). We utilized two specific elements in reference maps-flood extents and water depths. Since our reference maps were generated on the bare earth elevation, the DEM of bare earth in the five counties was adopted as the elevation data to be consistent. Also, in order to be consistent in comparison, we used water depths from reference flood maps instead of water levels from USGS or other sources as one of the inputs for HAND model in this case study. Missing data in both 100- and 500-year floodplain maps are marked with "no data" tag, meaning they would not play any role in the calculation. 


\subsection{Procedure of Calculating Draining Potential Using HAND}

As introduced by Rennó et al. (2008), the HAND procedure starts from DEM data. A sequence of minor modifications is applied to remove depressions and create a hydrologically coherent DEM (Jones, 2002; Lindsay and Creed, 2005; Nobre et al., 2016, 2011; Rennó et al., 2008). Several modification methods are acceptable (Garbrecht and Martz, 2002; Jones, 2002; Lindsay and Creed, 2005; Martz and Garbrecht, 1998; Rieger, 1998) in this step. Next, flow paths are obtained from the coherent DEM (Nobre et al., 2011) using flow direction calculating approaches, such as $D_{8}, D_{\infty}$ or the like (Holmgren, 1994; Mark, 1984; Quinn et al., 1991; Tarboton, 1997) and then drainage channels are determined through pixels with an accumulated value not less than the accumulated area threshold (Mark, 1984; Tarboton, 1997). Finally, the elevation of each DEM grid is normalized by subtracting the elevation of the nearest drainage point it drains to from its original elevation. The HAND value of each pixel obtained through the elevation normalization is the elevation difference between a pixel and its nearest drainage point. Detailed introduction of the HAND model and its steps can be found in the literature (Nobre et al., 2011; Rennó et al., 2008).

\subsection{Flood Inundation Mapping Based on HAND Model}

Different from hydrodynamic or hydrological models, HAND model does not require physical parameters like soil characteristics. Therefore, flood predictions made by HAND model cannot reflect the influences of soil characteristics or the water-soil interactions. However, this small deficiency did not prevent the HAND from becoming one of the most popular flood extents predicting tool. There are two approaches to obtain a flood extents map using HAND. The first approach is to carry out flood inundation mapping by combining HAND and National Hydrograph Dataset (NHD), introduced by Liu et al. (2016). This approach starts by generating HAND using DEM data and NHD flow line datasets. Then reach-averaged river geometry parameters are calculated, and the Manning's equation is applied to obtain a water stage heightstreamflow rating curve. Finally, given a streamflow value from other hydraulic models, such as the National Water Model (NWM), or a gauge point, such as the USGS measuring point, the corresponding water depth can be obtained, and the inundation areas can be calculated. Zheng et al. (2018) compared the river geometry parameters and the rating curve obtained using this approach with those derived from HEC-RAS and reported the results to be reasonable. Keane et al. (2016) realized an online application of viewing flood maps generated by NHD-HAND based on the Tethys Platform (https://www.tethysplatform.org/).

The other approach is more straightforward and closer to the original definition of the HAND model. Since the HAND value of each grid represents the relative height of the point over its nearest drainage pixel in mainstreams, by comparing a given water depth with the HAND value of each grid, we can separate the inundated pixels from the non-inundated ones. According to the 
concept of the HAND value, if a pixel has a HAND value less than the normalized water depth, it is considered as inundated. Normalized water depth is the depth normalized to the mainstream grid whose HAND value is 0 . Here we used the water depth near the outlet position. Since those outlets locate near the most downstream part of the study region, the water depths there do not need extra normalization. Some case studies accepted this more straightforward approach to calculate flood extents (McGrath et al., 2018; Nobre et al., 2016). We choose the straightforward method in this study since the real-time map system supports it.

\subsection{Comparative Analysis Design}

As one of the simplified- models, HAND model does not require as many inputs as hydrodynamic ones, but a few inputs are still required. The drainage threshold is a critical parameter since it distinguishes mainstream grids from those non-mainstream ones based on the total number of upstream grids that converge at the current point. In the model generation process, only the pixel with the number of accumulated grids that reaches or goes above the predefined threshold will be considered as grids in the mainstream. Those mainstream grids are the base points to which the elevations of the other grids are normalized. Therefore, changing the value of the threshold equals to the modification of the river networks. In general, a small threshold value will allow more grids in the mainstream, while a bigger one narrows the river network. Nobre et al. (2016) and Rennó et al. (2008) presented the impacts of changing threshold values on the shape of the river network and modeling results. Another parameter that affects the accuracy of modeling significantly is the water depth. Because all grids with a HAND value less than the given water depth are underwater, changing water depth will have a direct impact on the number of points considered inundated or not. The last parameter we chose was the resolution of the DEM for HAND generation. The resolution reflects how approximate the results are when comparing reference flood maps and HAND based ones. If the resolution difference is significant between the two maps, the HAND-based map will be less capable of reflecting the details of the study region. For example, if we compare a 50-meter-resolution HAND-based flood map with a 1-meter-resolution reference map, we need to set a single value for every 2,500 grids in reference ( 50 grids by height and 50 grids by width), even if the values of these 2,500 grids may be different from each other. By comparison, if we use a 5-meter HAND map, then only every 25 reference grids will share the same value, and we will preserve more variation. Moreover, DEM resolution has been proved to have impacts on local hydrological connectivity (López-Vicente and Álvarez, 2018) However, solutions for engineering problems always try to keep a balance between costs and benefits. The accuracy is obtained at the cost of computing time and storage expenses since vast amounts of grids require more significant memory and take a far longer time to process. Also, the largest region with 1-meter-resolution grids that the system can calculate is set to $5 \mathrm{~km}$ by $5 \mathrm{~km}$ due to browser memory limitations, making it less suitable for large scale analysis at $1 \mathrm{~m}$ resolution. Therefore, we focused on 5, 10, 25, 25-m-resolution data to compare. 

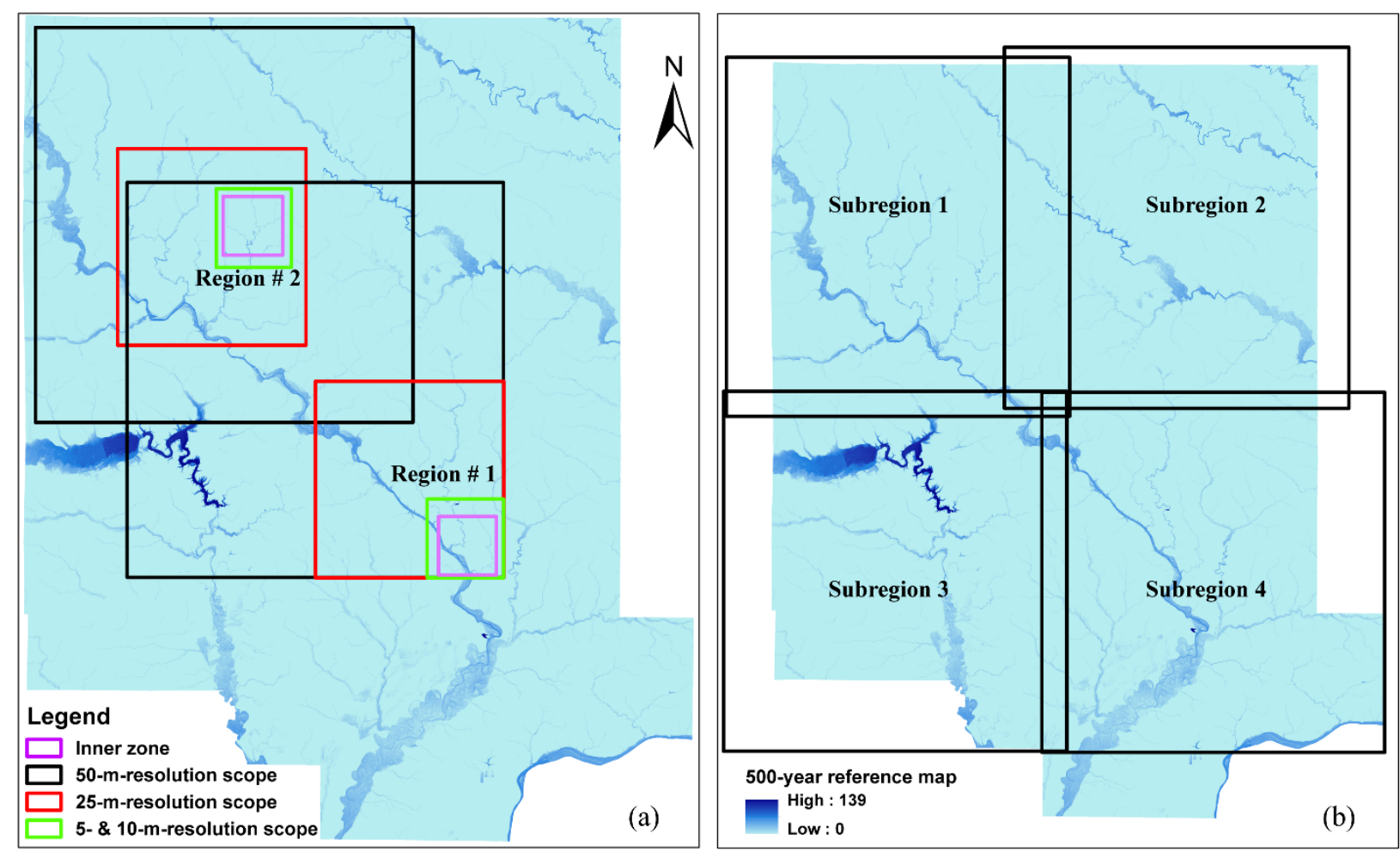

Figure 3. (a) Two regions selected to demonstrate the impacts of drainage threshold, water depth and DEM grid resolution (b) The division of the whole region into four $50 \mathrm{~km}$ by $50 \mathrm{~km}$ subregions with 25-meter-resolution grids

Our comparison analysis consists of three major components. First, we picked two small regions within the study area to demonstrate how three key parameters affect the accuracy of HAND flood extent maps. Both regions cover about $100 \mathrm{~km}^{2}$. As shown in Figure 3 (a), region \#1 locates around a segment of the main river channel and is divided into two parts by the river. Region \#1 has an average slope of $11.5^{\circ}$ and a standard deviation of $9.4^{\circ}$. By contrast, region \#2 sits in the upstream with a few smaller river branches inside. The average slope of region \#2 is $6.7^{\circ}$, with a standard deviation of $6.4^{\circ}$. In each round of comparison, we only changed one parameter in each parameter set and kept the other two unchanged. When testing the parameter influences in region \#1, we first adopted the water depth and drainage threshold of 17 feet and $4.0 \mathrm{~km}^{2}$ respectively, and changed the data resolution among 5-, 10-, 25-, and 50-m to see how the performance is varying. Then, we fixed the resolution to the best value obtained in the first step and kept the water depth unchanged as well when changing drainage threshold. Finally, with the resolution and drainage threshold fixed on the best value obtained in the first two steps, and we tested several water depth values around the outlet position. The detailed comparison study design in region \#1 and \#2 is listed in Table 1. There are a few points need to be explained: a) In theory, we could choose any drainage threshold value as long as it is smaller than the area of 
study region. However, in our testing, the next value to test depends completely on previous result and thus only a limited number of values would be tested. For example, if $4.5 \mathrm{~km}^{2}$ brings a better result than $4.0 \mathrm{~km}^{2}$, then the next value to test will probably be closer to 4.5 . As for water depth, since the reference flood extents maps are in DEM form, there are usually a few different water depth values available around the outlet point. b) Our testing method is not designed for finding the best global parameter set, as the best value determined in each step may not be in the final best parameter set. The first part of analysis is to demonstrate how the performance of HAND is varying under different parameter combinations and to act as a foundation for later analysis. As the second part of the analysis, we created a 10,000 $\mathrm{km}^{2}$ region using 50-meterresolution data which covers the five counties and determined the best combination of water depth and the threshold for this region (hereafter called regional analysis). Then, we divided the big region into four 25-meter-resolution subregions with the size of $50 \mathrm{~km}$ by $50 \mathrm{~km}$ and figured out the best parameter set for each subregion (hereafter called community-level analysis). In the second part, instead of testing possible water depths near the outlet position, we used three typical water depths - depth at the outlet $\left(D_{O}\right)$, weighted average depth $\left(D_{W}\right)$ among all inundated grids in reference floodplain maps, and the average water depth $\left(D_{A}\right)$ of the $D_{O}$ and the $D_{W}$. We adopted the depth at outlet position because of its clear physical meaning-it is the point where all branches in the upstream converge, so water depth picked here has the same meaning as those from hydrologic stations even though there is no real station. However, using only $D_{O}$ might create too many overestimations since the outlet point lies downstream, and the value is picked from the middle of the river's cross-section. Therefore, weighted average water depth is selected as our next testing choice because it reflects the average water depth on top of each inundated grid. We calculated the weighted average depth using Equation 1:

$$
D_{W}=\frac{\sum_{n} \text { Area }_{i} \times \text { Depth }_{i}}{\sum_{n} \text { Area }_{i}}
$$

Where $\mathrm{n}$ is the total number of inundated grids within the study scope, and $i$ represents each individual pixel. The shortcoming of $D_{W}$ is that it distributes water equally among all inundated grids. Thus, water depths of grids in main river channels tend to be lowered by the vast number of water-affected pixels that are not in the main channel or near the riverbank. Therefore, by arithmetically averaging $D_{O}$ and the $D_{W}$, we obtained an eclectic water depth $\left(D_{A}\right)$ that can reflect both the characteristics of all inundated grids and the outlet point. $D_{A}$ is the arithmetic average value of $D_{O}$ and $D_{W}$. Figure 3(b) presents the division of the 5-county region. Finally, we merged the best-matching HAND map of each subregion and compared the results with the one obtained by regional analysis. Areas that reach off the study scope will be ignored.

Also, allowing users to select study regions in real-time map system may cause areas to sit among multiple watersheds. Borders cutting across watersheds will create false accumulation values for grids near the border. As explained above, all upper stream grids that drain to the 
current point should be counted as its accumulating values. However, for positions near boundaries, the upper accumulating grids that go outside the border will be ignored and will lower the accumulation values for grids near borders. Therefore, the shape of the river network may change because of this. Creating an inner zone will help address the border problem since we ignore grids affected by border issues and thus can obtain a more consistent result.

\subsection{Model Comparison Metrics}

We applied quantitative measures, together with the non-quantitative ones to evaluate the performance of HAND-based flood maps by comparing them with the reference floodplain maps. For a pixel in a flood map, there are just two possible statuses, inundated or not inundated, in both model predictions and real situations. Therefore, we developed a two by two Error Matrix (Congalton and Green, 2019; Wilks, 2011) or called Confusion Matrix (Provost, 1998) to represent the status of a pixel. As shown in Figure 4, we use Positive or Negative to describe whether a pixel is inundated in HAND model or not, and True and False to indicate if the prediction is correct taking the reference as the real value.

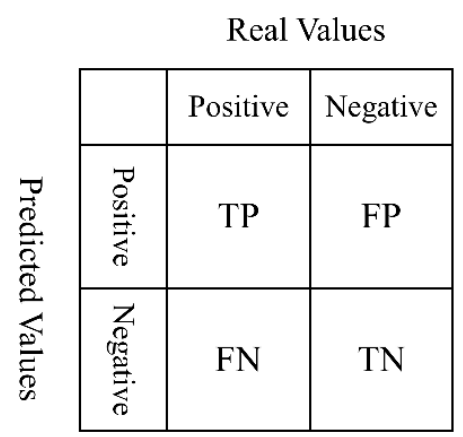

Figure 4. The matrix to evaluate the consistency of model results and references, where TP means inundated grids both in reference map and model results, FP means inundated grids in model results but not in reference map, FN means inundated grids in reference map but not in model results, and TN means dry grids in both reference map and model results

Researchers have suggested various measures to assess the ability of a model to give good predictions (Congalton and Green, 2019; Wilks, 2011). However, most of the indexes are partial and incomplete representations of the performance, and therefore should be applied together with each other (Wilks, 2011). Here, we adopted the Proportion Correct (PC), Bias Ratio (B), Hit Rate $(\mathrm{H})$, Kappa index (K), and Fitness-statistic (F) to evaluate the performance of HAND model. Readers may find a detailed description of these indexes in the relevant literature (Landis and Koch, 1977; Wilks, 2011). 
The Proportion Correct (PC) stands for the most direct and intuitive correct ratio, and it does not discriminate True-Positive points from True-Negative ones. The best possible PC value is 1. PC is calculated as in Equation 2:

$$
P C=\frac{T P+T N}{T P+F N+F P+T N}
$$

The Bias (B) is the ratio of the number of inundated pixels in the HAND flood map to the number of inundated pixels in the reference maps. A Bias value higher than 1 means the HAND model tends to predict more than the event occurs, or in other words, a tendency of overestimating. B is calculated as in Equation 3:

$$
B=\frac{T P+F P}{T P+F N}
$$

The Hit Rate $(\mathrm{H})$ demonstrates the ability of the HAND model to make correct predictions when the event occurs. The best possible value of $\mathrm{H}$ is 1 . $\mathrm{H}$ is calculated as in Equation 4:

$$
H=\frac{T P}{T P+F N}
$$

Kappa value $(\mathrm{K})$ is a ratio that measures the actual agreement between two models to the chance of agreement (Afshari et al., 2018; Landis and Koch, 1977). Afshari et al. (2018) indicate that a good $\mathrm{K}$ value is possible if the number of correctly-predicted dry pixels is far more than that of the correctly-predicted inundated ones, even the model is failing in detecting inundated grids correctly. The best possible value of the Kappa value is 1 and is calculated as in Equation 5:

$$
K=\frac{N(T P+T N)-((T P+F P) \times(T P+F N)+(F P+T N) \times(F N+T N))}{N^{2}-((T P+F P) \times(T P+F N)+(F P+T N) \times(F N+T N))}
$$

Fitness-statistic ( $\mathrm{F}$ ) is often taken as a supplement to $\mathrm{K}$ to address the shortcoming of $\mathrm{K}$ value mentioned above. F value stresses more on the consistency of inundated pixels in both flood maps. $\mathrm{F}$ is calculated as in Equation 6:

$$
F=\frac{T P}{T P+F P+F N}
$$

PC, $\mathrm{H}, \mathrm{K}$, and F are commonly used to evaluate the model performance. However, literature is limited when it comes to interpreting the results when these four indexes are not entirely consistent with each other. In our cases, there are situations when PC goes up, $\mathrm{H}$ goes down, or when $\mathrm{H}$ increases, both $\mathrm{K}$ and $\mathrm{F}$ decrease. Thus, we utilized a dimensionless mixed index to address that problem. As introduced above, we should keep both $\mathrm{K}$ and $\mathrm{F}$ since they focus on non-inundated grids and inundated ones. We also accepted $\mathrm{H}$, as Hit Rate is a widely used index in evaluating model performance, and it focuses more on how many inundated pixels are 
distinguished by the HAND mode. Equation 7 shows how the Mixed Index (hereafter called MI) is calculated:

$$
M I=H+K+F
$$

\section{Results and Discussion}

\subsection{Flood Extents with Different Parameter Settings in Two Small Regions}

Table 1 summarizes the performance of flood extent estimation in Region \#1 and \#2 and shows how changes in HAND model parameters (resolution, threshold, and water depth) affect the accuracy of flood extents maps in 500-year flood event. The best performance in each region is bolded and underlined in Table 1 . The results suggest that the HAND model's resolution has a more significant impact compared to the other two parameters. As analyzed in the previous section, the resolution reflects how many details in the reference maps are captured when compared. Also, this indicates the importance of the quality of references, since an incorrect or a rough reference map will harm the matching ratio. Such results have also been reported by Garousi-Nejad et al. (2019). Their study showed the application of a higher-resolution DEM (3$\mathrm{m}$ ) could improve the Fit Metric Value and Correctness Metric compared to those from the 10-m data. Findings reported by Munoth and Goyal (2019) and Dai et al. (2019) also suggested that the data resolution should be carefully chosen in order to get a good modeling result. Figure 5 shows the best matching scenarios in Region \#1 and \#2 of the 500-year flood event.

Table 1 The performance summary of the HAND-based flood extents predictions in 500-year flood event using different parameters in region \#1 and \#2. Where PC stands for Proportion Correct, $\mathrm{H}$ stands for Hit

Rate, K stands for Kappa value, F stands for Fitness-statistic, and MI stands for Mixed Index.

\begin{tabular}{ccccccccc}
\hline $\begin{array}{c}\text { Study } \\
\text { Region }\end{array}$ & $\begin{array}{c}\text { DEM Resolution } \\
(\mathrm{m})\end{array}$ & $\begin{array}{c}\text { Water Depth } \\
(\mathrm{ft} .)\end{array}$ & $\begin{array}{c}\text { Drainage Threshold } \\
\left(\mathrm{km}^{2}\right)\end{array}$ & PC & H & K & F & MI \\
\hline & 5 & 17 & 4.0 & 0.95 & 0.96 & 0.83 & 0.75 & 2.55 \\
& 10 & 17 & 4.0 & 0.94 & 0.97 & 0.80 & 0.72 & 2.50 \\
& 25 & 17 & 4.0 & 0.93 & 0.94 & 0.77 & 0.68 & 2.40 \\
Region & 50 & 17 & 4.0 & 0.92 & 0.92 & 0.74 & 0.65 & 2.32 \\
$\# 1$ & 5 & 17 & 3.0 & 0.95 & 0.96 & 0.84 & 0.76 & 2.57 \\
& 5 & 17 & 3.5 & 0.95 & 0.97 & 0.84 & 0.76 & 2.58 \\
& 5 & 17 & 3.7 & 0.95 & 0.96 & 0.84 & 0.76 & 2.57 \\
& 5 & 17 & 4.5 & 0.95 & 0.95 & 0.83 & 0.76 & 2.55 \\
\hline
\end{tabular}




\begin{tabular}{ccccccccc}
\hline & $\mathbf{5}$ & $\mathbf{1 6}$ & $\mathbf{3 . 5}$ & $\underline{\mathbf{0 . 9 6}}$ & $\underline{\mathbf{0 . 9 5}}$ & $\underline{\mathbf{0 . 8 6}}$ & $\underline{\mathbf{0 . 7 9}}$ & $\underline{\mathbf{2 . 6 0}}$ \\
& 5 & 18 & 3.5 & 0.94 & 0.98 & 0.82 & 0.74 & 2.55 \\
& 5 & 19 & 3.5 & 0.94 & 0.98 & 0.82 & 0.74 & 2.55 \\
\hline \multirow{2}{*}{ Region } & 5 & 16 & 4.0 & 0.94 & 0.96 & 0.66 & 0.53 & 2.16 \\
& 10 & 16 & 4.0 & 0.93 & 0.96 & 0.64 & 0.51 & 2.12 \\
& 25 & 16 & 4.0 & 0.91 & 0.96 & 0.57 & 0.44 & 1.98 \\
& 50 & 16 & 4.0 & 0.91 & 0.95 & 0.56 & 0.43 & 1.95 \\
& 5 & 16 & 3.0 & 0.93 & 0.97 & 0.64 & 0.51 & 2.13 \\
& 5 & 16 & 3.5 & 0.94 & 0.96 & 0.66 & 0.53 & 2.16 \\
& 5 & 16 & 3.7 & 0.94 & 0.96 & 0.66 & 0.53 & 2.16 \\
& 5 & 16 & 4.5 & 0.95 & 0.94 & 0.69 & 0.55 & 2.19 \\
& 5 & 16 & 4.7 & 0.95 & 0.92 & 0.69 & 0.56 & 2.18 \\
& 5 & 16 & 5.0 & 0.95 & 0.92 & 0.69 & 0.56 & 2.18 \\
& 5 & 18 & 5.0 & 0.92 & 0.97 & 0.61 & 0.48 & 2.06 \\
& 5 & 17 & 5.0 & 0.93 & 0.94 & 0.64 & 0.50 & 2.09 \\
& 5 & 15 & 5.0 & 0.95 & 0.92 & 0.69 & 0.56 & 2.18 \\
& 5 & 14 & 5.0 & 0.95 & 0.91 & 0.70 & 0.57 & 2.18 \\
& 5 & $\mathbf{1 3}$ & 5.0 & $\underline{\mathbf{0 . 9 7}}$ & $\underline{\mathbf{0 . 8 6}}$ & $\underline{\mathbf{0 . 7 6}}$ & $\underline{\mathbf{0 . 6 3}}$ & $\underline{\mathbf{2 . 2 5}}$ \\
\hline
\end{tabular}

As shown in Table 1, all indexes except for PC are better in region \# 1 than those in region \# 2. We believe this is mainly because of the topological difference between the two regions described in the previous section. However, the two images in Figure 5 still show some similarities - the predictions in the main channel in each image were acceptable, and overestimations were more common among small branches.

\subsection{Regional vs. Community-Level Analysis}

We first calculated the five-county region using the regional approach. Table 2 shows the flood extents comparison using $D_{O}, D_{W}$, and $D_{A}$ in the 100- and 500-year flood event, where the best performance in each region is bolded and underlined. TP, FP, FN, TN values are shown using the percentage of the numbers of the classified grids within the study scope of the total 2,960,740 and 2,945,656 points, respectively. The number of grids is different because the missing data regions in the 100-year reference are slightly different from those in the 500-year reference map. 

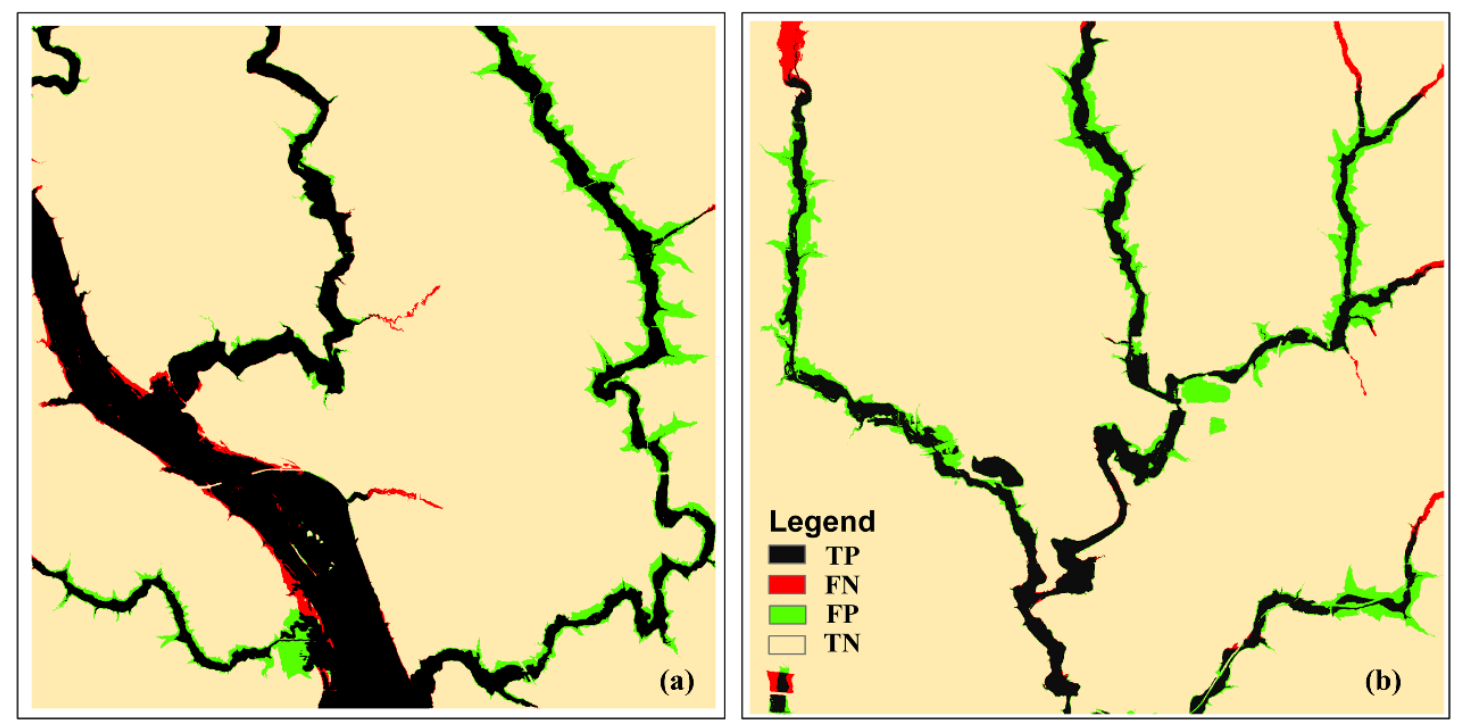

Figure 5. Best matching scenario for two regions in the 500-year flood event (a) Region \#1, (b) Region \#2

Table 2 Flood modeling results using different water depths by the regional approach. Where $D_{O}$ stands for water depth at the outlet, $D_{W}$ stands for the weighted average depth, and $D_{A}$ is the average of $D_{O}$ and $D_{W}$.

\begin{tabular}{cccccccccccc}
\hline $\begin{array}{c}\text { Flood event } \\
\text { (Return Period) }\end{array}$ & \multicolumn{2}{c}{$\begin{array}{c}\text { Water Depth } \\
(\mathrm{ft.})\end{array}$} & $\begin{array}{c}\text { TP } \\
(\%)\end{array}$ & $\begin{array}{c}\text { FP } \\
(\%)\end{array}$ & $\begin{array}{c}\text { FN } \\
(\%)\end{array}$ & $\begin{array}{c}\text { TN } \\
(\%)\end{array}$ & PC & H & K & F & MI \\
\hline \multirow{2}{*}{ 100-year } & $\boldsymbol{D}_{\boldsymbol{o}}$ & $\mathbf{9 . 0 0}$ & $\underline{\mathbf{9 . 0 1}}$ & $\underline{\mathbf{4 . 5 2}}$ & $\underline{\mathbf{2 . 2 0}}$ & $\underline{\mathbf{8 4 . 2 7}}$ & $\underline{\mathbf{0 . 9 3}}$ & $\underline{\mathbf{0 . 8 0}}$ & $\underline{\mathbf{0 . 6 9}}$ & $\underline{\mathbf{0 . 5 7}}$ & $\underline{\mathbf{2 . 0 6}}$ \\
& $D_{W}$ & 6.81 & 8.12 & 3.39 & 3.08 & 85.41 & 0.94 & 0.73 & 0.68 & 0.56 & 1.97 \\
& $D_{A}$ & 7.91 & 9.01 & 4.52 & 2.20 & 84.27 & 0.93 & 0.80 & 0.69 & 0.57 & 2.06 \\
\hline \multirow{2}{*}{ 500-year } & $D_{O}$ & 10.00 & 9.53 & 4.16 & 2.52 & 83.79 & 0.93 & 0.79 & 0.70 & 0.59 & 2.08 \\
& $D_{W}$ & 7.85 & 9.35 & 3.77 & 2.70 & 84.18 & 0.94 & 0.78 & 0.71 & 0.59 & 2.08 \\
& $\boldsymbol{D}_{\boldsymbol{A}}$ & $\mathbf{8 . 9 2}$ & $\underline{\mathbf{9 . 3 5}}$ & $\underline{\mathbf{3 . 7 7}}$ & $\underline{\mathbf{2 . 7 0}}$ & $\underline{\mathbf{8 4 . 1 8}}$ & $\underline{\mathbf{0 . 9 4}}$ & $\underline{\mathbf{0 . 7 8}}$ & $\underline{\mathbf{0 . 7 1}}$ & $\underline{\mathbf{0 . 5 9}}$ & $\underline{\mathbf{2 . 0 8}}$ \\
\hline
\end{tabular}

The first and last record of the 100-year flood in Table 2 is the same because the region lacks the value of 8 feet in the HAND matrix, which is the same reason why the last two records of 500year flood events in the table are the same.

In the community-level analysis, we tested the performance using different parameter sets, and the best parameter set was selected for each subregion in Figure 3(b). Figure 6 shows the variation of the MI in each subregion in the 100- and the 500-year flood events when HAND

$$
-16 \text { - }
$$


model parameters vary. The blue line represents the 100-year flood event, and the red line represents the 500-year one. Figure 6 indicates that there is no parameter set that can guarantee the best modeling results in all cases. The fact that the optimal set varies from different subregions suggests that the best model parameters may be affected by the intrinsic characters of that region, such as averaged slope, river network density, etc. Dai et al. (2019) had come to the same conclusion as their results showed the morphology of the study region has a direct impact on resolution effects. Thus, the optimal parameter value for one region may not work as well for another. However, a few similar results are shared among subregions. First, the results generated using outlet water depth are similar to those using average water depth. Second, results using outlet water depth and average water depth are better than that using the weighted average depth in both 100- and 500-year flood events in all subregions except for subregion 3. In subregion 3, the performances of three water depths are quite similar in the 100-year flood case, while the weighted average depth outperformed the other two in the 500-year flood event.
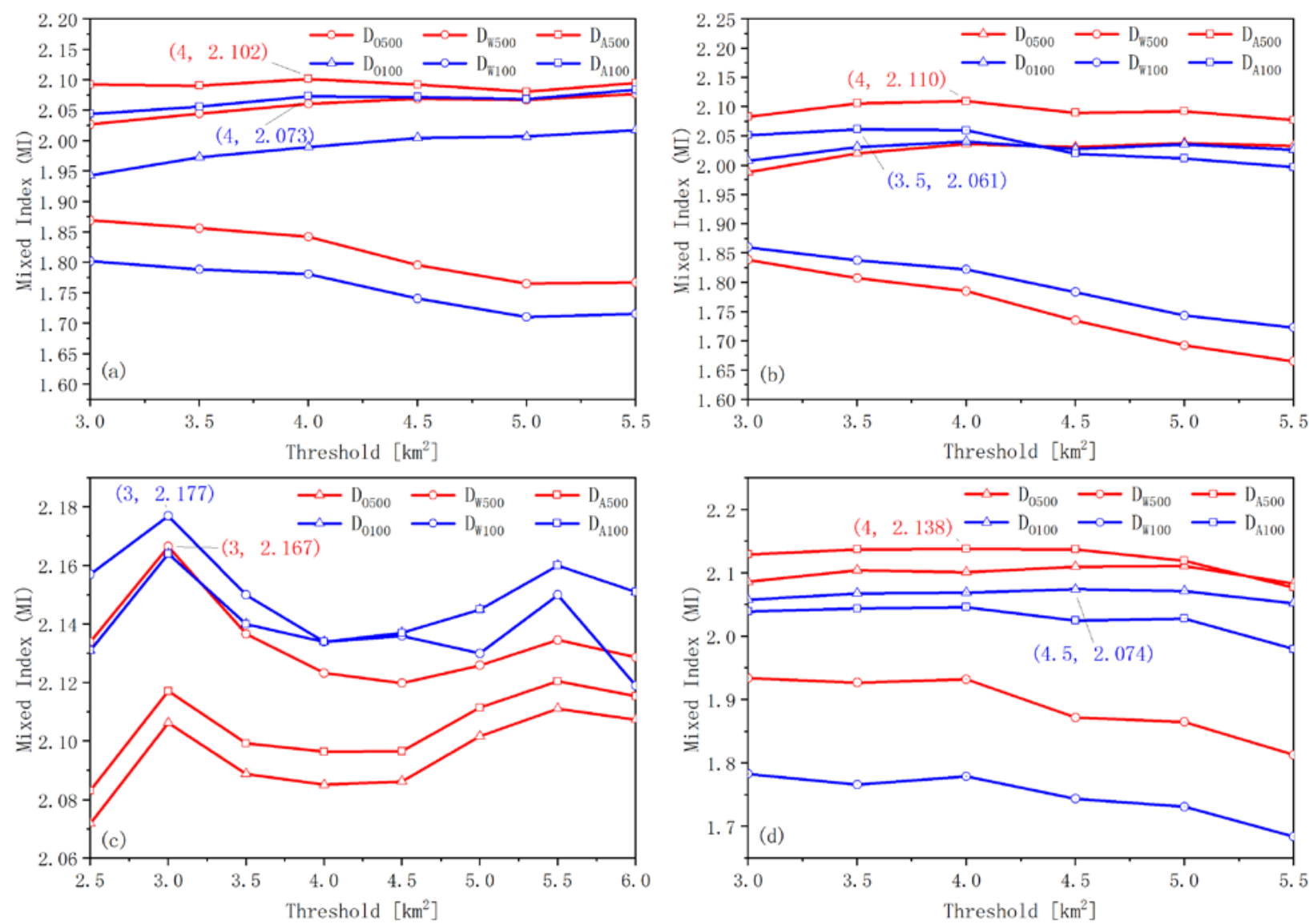

Figure 6. Flood extent evaluation under different parameter settings in four subregions (a) subregion 1; (b) subregion 2; (c) subregion 3; (d) subregion 4 
Nobre et al. (2016) demonstrated the impacts of drainage threshold on the performance of HAND as they successfully reduced overestimation to $25.95 \%$ by increasing the drainage threshold value from $0.405 \mathrm{~km}^{2}$ to $4.05 \mathrm{~km}^{2}$. Our results demonstrated the stable performance of the threshold value of $4.0 \mathrm{~km}^{2}$, with half of the parameter sets having the $4.0 \mathrm{~km}^{2}$ threshold. In our case, all threshold values of the best parameter sets fall between $3.0 \mathrm{~km}^{2}$ and $4.5 \mathrm{~km}^{2}$. But still, the best threshold value varies slightly among subregions. Figures 7 and 8 show the inundation maps using the best parameter set for all subregions in the 100- and 500-year flood events. The outer black boxes show the true scope of each subregion. The details of the best performances in each subregion are listed in Table 3.

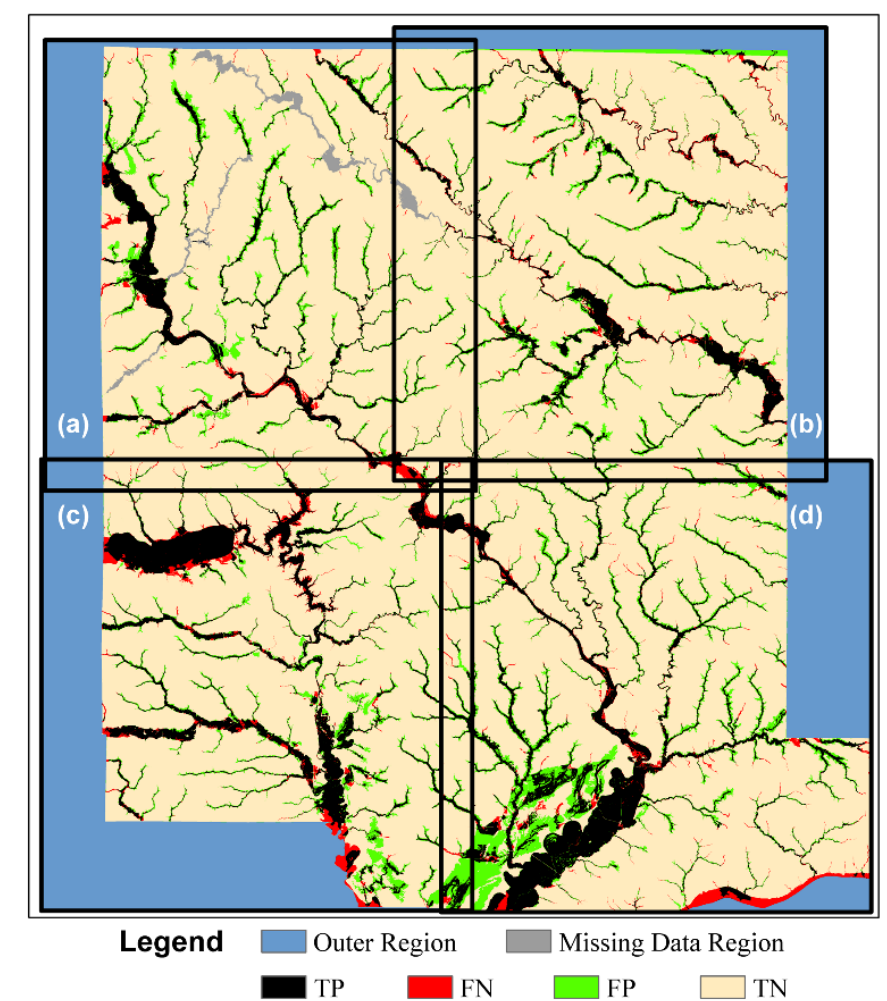

Figure 7. Best predictions for each subregion in the 100-year flood event (a) subregion 1; (b) subregion 2; (c) subregion 3; (d) subregion 4 


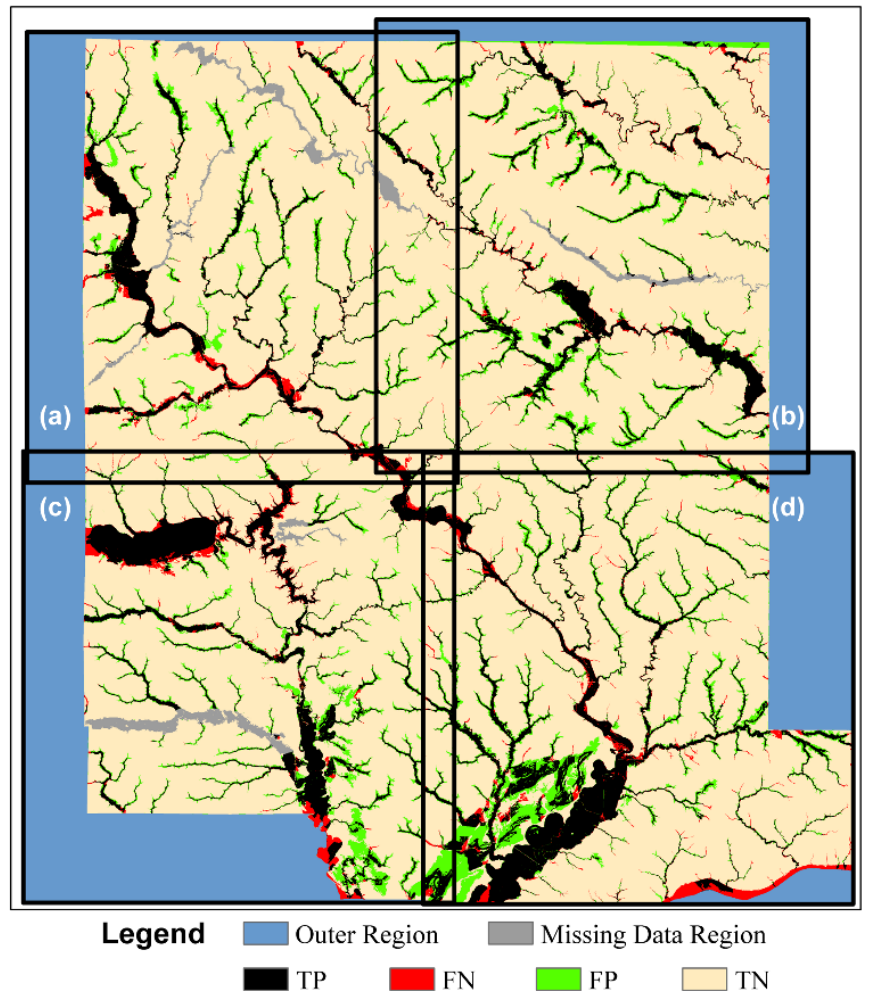

Figure 8. Best predictions for each subregion in the 500-year flood event (a) subregion 1; (b) subregion 2; (c) subregion 3; (d) subregion 4

Table 3 The best predictions in each subregion in the 100-year and 500-year flood events with parameters

\begin{tabular}{|c|c|c|c|c|c|c|c|c|c|c|c|c|c|}
\hline \multirow{2}{*}{$\begin{array}{l}\text { Flood } \\
\text { Event }\end{array}$} & \multicolumn{2}{|c|}{ Parameter Set } & \multirow[b]{2}{*}{ Region } & \multirow{2}{*}{$\begin{array}{l}\mathrm{TP} \\
(\%)\end{array}$} & \multirow{2}{*}{$\begin{array}{l}\text { FP } \\
(\%)\end{array}$} & \multirow{2}{*}{$\begin{array}{l}\text { FN } \\
(\%)\end{array}$} & \multirow{2}{*}{$\begin{array}{l}\mathrm{TN} \\
(\%)\end{array}$} & \multirow[b]{2}{*}{ PC } & \multirow[b]{2}{*}{ B } & \multirow[b]{2}{*}{$\mathrm{H}$} & \multirow[b]{2}{*}{$\mathrm{K}$} & \multirow[b]{2}{*}{ F } & \multirow[b]{2}{*}{ MI } \\
\hline & $\begin{array}{c}\text { Water Depth } \\
\text { (ft.) }\end{array}$ & $\begin{array}{c}\text { Threshold } \\
\left(\mathrm{km}^{2}\right)\end{array}$ & & & & & & & & & & & \\
\hline \multirow{4}{*}{ 100-year } & $D_{A}=10.9$ & 4.0 & 1 & 6.9 & 5.0 & 1.0 & 87.1 & 0.94 & 1.51 & 0.87 & 0.66 & 0.53 & 2.06 \\
\hline & $D_{A}=8.9$ & 3.5 & 2 & 6.6 & 4.3 & 1.3 & 87.8 & 0.94 & 1.38 & 0.84 & 0.68 & 0.55 & 2.07 \\
\hline & $D_{W}=9.9$ & 3.0 & 3 & 12.1 & 4.7 & 2.5 & 80.7 & 0.92 & 1.15 & 0.82 & 0.72 & 0.62 & 2.16 \\
\hline & $D_{O}=12.0$ & 4.5 & 4 & 11.3 & 7.0 & 1.9 & 79.8 & 0.91 & 1.38 & 0.85 & 0.66 & 0.56 & 2.07 \\
\hline \multirow{4}{*}{ 500-year } & $D_{A}=11.4$ & 4.0 & 1 & 7.6 & 4.3 & 1.5 & 86.6 & 0.94 & 1.30 & 0.84 & 0.69 & 0.57 & 2.10 \\
\hline & $D_{A}=11.8$ & 4.0 & 2 & 7.6 & 5.2 & 1.0 & 86.2 & 0.94 & 1.48 & 0.88 & 0.68 & 0.55 & 2.11 \\
\hline & $D_{W}=11.6$ & 3.0 & 3 & 12.4 & 5.7 & 2.2 & 79.7 & 0.92 & 1.24 & 0.85 & 0.71 & 0.61 & 2.17 \\
\hline & $D_{A}=10.1$ & 4.0 & 4 & 12.5 & 6.4 & 2.1 & 79.0 & 0.91 & 1.29 & 0.85 & 0.69 & 0.59 & 2.13 \\
\hline
\end{tabular}


Table 3 shows that HAND flood extents maps successfully predicted most inundated grids in reference floodplain maps, with $\mathrm{H}$ reaching at least $82.0 \%$, PC above $91.0 \%$, and Kappa value more significant than 0.6 in all cases. According to Landis and Koch (1977), Kappa value higher than 0.6 indicates a substantial agreement with the reference maps. B higher than one means HAND predictions in all four subregions tend to overestimate more than underestimate. This has also been demonstrated by Figures 7 and 8, as green areas (overestimated areas) look more prominent than red areas (underestimated areas). We noticed that compared to small branches, major channels are better predicted as fewer mismatchings appearing around large channels than smaller ones. Afshari et al. (2018) reported the $\mathrm{K}$ and $\mathrm{F}$ values to be 0.88 and 0.53 respectively in the Black Warrior River they tested when comparing HAND model and the FEMA 100-year reference map. The reported $\mathrm{K}$ value in that case is significantly higher than ours. However, we think this is mainly because of the region size. The Black Warrior River domain they tested is only about $62 \mathrm{~km}^{2}$, a little more than half of the smallest regions in our study. Bigger region means more different physiographic characteristics to be included in a single round of modeling, and thus will probably lower the model performance.
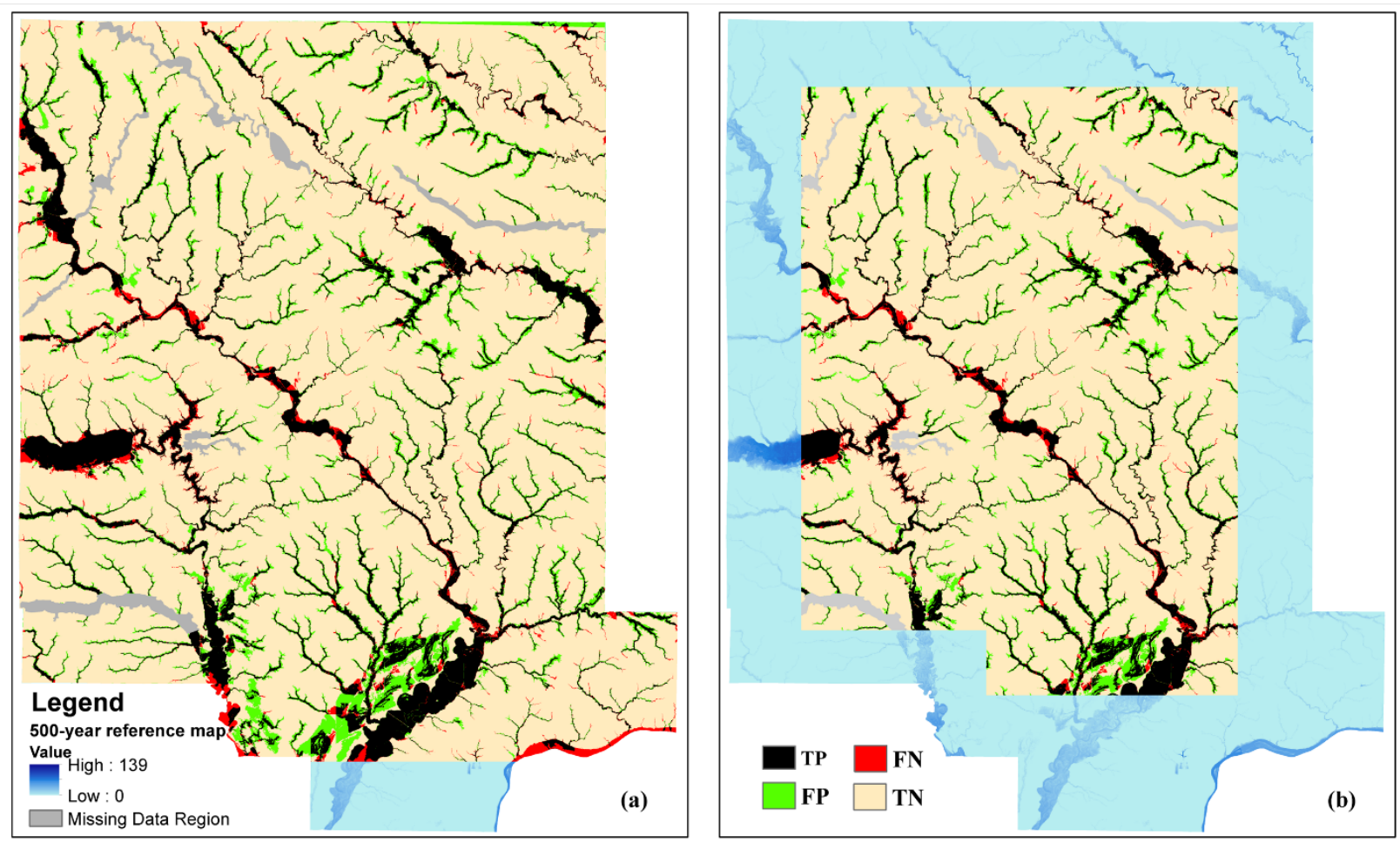

Figure 9. Predictions in 500-year event after mosaicking the best results in four subregions and the inner area creation (a) mosaicked flood extents in 4 subregions; (b) the internal zone of (a) 


\subsection{Final Comparison}

As the last part of the analysis, we mosaicked the best matching scenario of the four subregions together and compare the mosaicked result with the one from the regional approach.

Furthermore, we created an inner zone to address the border issue. Figure 9 illustrates the best matching predictions after merging and the creation of the inner zone in the 500-year flood events. The values of the overlapping area among subregions were from the best matching subregion. Improvements in modeling accuracy because of the mosaicking process and the internal zone creation are listed in Table 4.

Table 4 Comparison of modeling results using different approaches

\begin{tabular}{|c|c|c|c|c|c|c|c|c|c|c|c|c|}
\hline $\begin{array}{l}\text { Flood } \\
\text { Event }\end{array}$ & $\begin{array}{c}\text { Calculation } \\
\text { Approach }\end{array}$ & $\begin{array}{l}\mathrm{TP} \\
(\%)\end{array}$ & $\begin{array}{l}\text { FP } \\
(\%)\end{array}$ & $\begin{array}{l}\text { FN } \\
(\%)\end{array}$ & $\begin{array}{l}\mathrm{TN} \\
(\%)\end{array}$ & Total Grids & PC & B & $\mathrm{H}$ & K & F & MI \\
\hline \multirow{3}{*}{$\begin{array}{l}100- \\
\text { year }\end{array}$} & $\begin{array}{l}\text { region as a } \\
\text { whole }\end{array}$ & 9.01 & 4.52 & 2.20 & 84.27 & $2,960,740$ & 0.93 & 1.21 & 0.80 & 0.69 & 0.57 & 2.06 \\
\hline & mosaic & 9.58 & 5.41 & 1.68 & 83.33 & $11,756,660$ & 0.93 & 1.33 & 0.85 & 0.69 & 0.57 & 2.11 \\
\hline & $\begin{array}{l}\text { inner zone of } \\
\text { the } \\
\text { mosaicked } \\
\text { region }\end{array}$ & 9.09 & 5.04 & 1.28 & 84.59 & $7,012,049$ & 0.94 & 1.36 & 0.88 & 0.71 & 0.59 & 2.18 \\
\hline \multirow{3}{*}{$\begin{array}{l}\text { 500- } \\
\text { year }\end{array}$} & $\begin{array}{l}\text { region as a } \\
\text { whole }\end{array}$ & 9.35 & 3.77 & 2.70 & 84.18 & $2,945,656$ & 0.94 & 1.09 & 0.78 & 0.71 & 0.59 & 2.08 \\
\hline & mosaic & 10.42 & 5.48 & 1.72 & 82.38 & $11,700,281$ & 0.92 & 1.31 & 0.86 & 0.70 & 0.59 & 2.15 \\
\hline & $\begin{array}{c}\text { inner zone of } \\
\text { the } \\
\text { mosaicked } \\
\text { region }\end{array}$ & 9.87 & 5.10 & 1.36 & 83.67 & $6,970,707$ & 0.94 & 1.33 & 0.88 & 0.72 & 0.60 & 2.20 \\
\hline
\end{tabular}

As Table 4 shows, the community-level approach helps improve H. However, other indexes did not improve or failed to remain unchanged as $\mathrm{H}$ and MI increased. Compared to the mosaicked region, the inner zone improved PC, $\mathrm{H}, \mathrm{K}$, and $\mathrm{F}$. The approach of community-level calculation helped MI increased by $2.4 \%$ (the 100-year flood event) and $3.4 \%$ (the 500-year flood event) compared to the regional calculating approach. The inner zone increased MI by $3.3 \%$ (100-year flood) and $2.3 \%$ (500-year flood), compared to the results using the community-level approach. However, we believe that different from calculating big regions at a community level, the inner 
zone approach should be carefully applied. Only when the model border cuts across watersheds, should it be considered. If the boundaries of the study region and watershed overlap, then no inner zone should be used.

\section{Conclusions}

In this study, we evaluated how flood extent predictions by a simplified- model-HAND (Height Above the Nearest Drainage) change under different parameter settings and how they could be used to improve the model results without involving additional data sources. The results demonstrated the capacity of the HAND model to give acceptable flood extent predictions, even using the coarsest DEM data with no additional improving methods involved. In the basic case, the Hit Rate reaches 0.80 (0.79 for the 500-year event), Proportion Correct reaches 0.93, and Kappa Value reaches 0.69 (0.70 for the 500-year event). The results clearly showed that the performance of HAND model is influenced by its parameters, namely, water depth, drainage threshold and data resolution. Although the best parameter value may vary among regions, our study suggested a few practical values to improve HAND performance-for water depth, $D_{O}$, $D_{W}$, and $D_{A}$ could be tested first to see if any of them brings a satisfying improvement. Similarly, a few drainage thresholds close to $4.0 \mathrm{~km}^{2}$ could be tested before trials on more specific values. In addition, the creation of buffer zones around the border helps make a comprehensive improvement for PC, H, K, and F values. In our case study, the final MI improved by $5.83 \%$ and $5.77 \%$ in the 100- and 500-year flood events respectively, compared to the original values. However, despite the effect of the inner-zone approach, we suggested that it should not be applied unless the study scope is cutting across watersheds.

The approaches suggested in this research is like creating a patch for large-scale flood inundation modeling. A coarser data with fewer adjustments should be applied for a large region to guarantee the efficiency of simulation, while a finer parameter set could be utilized in a few specific subregions to improve local performance. Findings in this study may benefit large-scale modeling using the HAND method or other simplified models.

Despite the favorable findings in this study, we find it necessary to run large-scale analyses to discover more physical rules behind the phenomenon. Less data requirement is a double-edged sword-it makes the simplified models easy to use on one hand while makes models heavily dependent on each input on the other hand. One major factor that impairs the portability of these models is physiographic differences among regions. Although many researchers have made suggestions about the optimal range of parameters, most of the ranges are obtained directly from the region they studied and haven't been tested in multiple regions. Determining a general parameter range that is applicable to various regions for simplified models could be considered as future work. 


\section{Acknowledgements:}

The floodplain maps used as references were made available by the statewide mapping project at the Iowa Flood Center.

\section{References}

Afshari, S., Tavakoly, A.A., Rajib, M.A., Zheng, X., Follum, M.L., Omranian, E., Fekete, B.M., 2018. Comparison of new generation low-complexity flood inundation mapping tools with a hydrodynamic model. J. Hydrol. 556, 539-556.

https://doi.org/10.1016/j.jhydrol.2017.11.036

Agliamzanov, R., Sit, M., Demir, I., 2020. Hydrology@Home: a distributed volunteer computing framework for hydrological research and applications. J. Hydroinformatics 22, 235-248. https://doi.org/10.2166/hydro.2019.170

Arrighi, C., Brugioni, M., Castelli, F., Franceschini, S., Mazzanti, B., 2013. Urban micro-scale flood risk estimation with parsimonious hydraulic modelling and census data. Nat. Hazards Earth Syst. Sci. 13, 1375-1391. https://doi.org/10.5194/nhess-13-1375-2013

Bukhari, S., 2016. Impact of Floods in Pakistan: Historical and Socio-Economic Perspective (1970-2010). Islamia University.

Carson, A., Windsor, M., Hill, H., Haigh, T., Wall, N., Smith, J., Olsen, R., Bathke, D., Demir, I., Muste, M., 2018. Serious gaming for participatory planning of multi-hazard mitigation. Int. J. River Basin Manag. 16, 379-391. https://doi.org/10.1080/15715124.2018.1481079

Cœur, D., 2017. Flood Management in France from 18th to 20th Centuries: A State Issue? Floods 2, 1-13. https://doi.org/10.1016/B978-1-78548-269-4.50001-9

Congalton, R.G., Green, K., 2019. Assessing the Accuracy of Remotely Sensed Data: Principles and Practices, CRC press.

Dai, W., Yang, X., Na, J., Li, J., Brus, D., Xiong, L., Tang, G., Huang, X., 2019. Effects of DEM resolution on the accuracy of gully maps in loess hilly areas. Catena 177, 114-125. https://doi.org/10.1016/j.catena.2019.02.010

de Lollo, J.A., Marteli, A.N., Lorandi, R., 2019. Flooding Susceptibility Identification Using the HAND Algorithm Tool Supported by Land Use/Land Cover Data, in: IAEG/AEG Annual Meeting Proceedings, San Francisco, California, 2018 - Volume 2. Springer International Publishing, pp. 107-112. https://doi.org/10.1007/978-3-319-93127-2_16

Demir, I., Szczepanek, R., 2017. Optimization of river network representation data models for web-based systems. Earth Sp. Sci. 4, 336-347. https://doi.org/10.1002/2016EA000224

Demir, I., Yildirim, E., Sermet, Y., Sit, M.A., 2018. FLOODSS: Iowa flood information system as a generalized flood cyberinfrastructure. Int. J. River Basin Manag. 16, 393-400. https://doi.org/10.1080/15715124.2017.1411927

Ebert-Uphoff, I., Thompson, D.R., Demir, I., Gel, Y.R., Hill, M.C., Karpatne, A., Guereque, M., Kumar, V., Cabral-Cano, E., Smyth, P., 2017. A Vision For The Development Of 
Benchmarks To Bridge Geoscience And Data Science, in: 7th International Workshop on Climate Informatics.

Garbrecht, J., Martz, L., 2002. Channel Network Delineation and Watershed Segmentation in the TOPAZ Digital Landscape Analysis System, in: GIS for Water Resource and Watershed Management. pp. 7-16. https://doi.org/10.1201/9780203217917.ch1

Garousi-Nejad, I., Tarboton, D.G., Aboutalebi, M., Torres-Rua, A.F., 2019. Terrain Analysis Enhancements to the Height Above Nearest Drainage Flood Inundation Mapping Method. Water Resour. Res. 55, 7983-8009. https://doi.org/10.1029/2019WR024837

Gilles, D., Young, N., Schroeder, H., Piotrowski, J., Chang, Y.J., 2012. Inundation mapping initiatives of the iowa flood center: Statewide coverage and detailed urban flooding analysis. Water (Switzerland) 4, 85-106. https://doi.org/10.3390/w4010085

Godbout, L., Zheng, J.Y., Dey, S., Eyelade, D., Maidment, D., Passalacqua, P., 2019. Error Assessment for Height Above the Nearest Drainage Inundation Mapping. J. Am. Water Resour. Assoc. 55, 952-963. https://doi.org/10.1111/1752-1688.12783

Gutenson, J., Follum, M., Snow, A., Wahl, M., 2017. Large-Scale Flood Inundation Modeling in Data Sparse Environments using TanDEM-X Terrain Data. Open Water J. 4.

Hammond, M.J., Chen, A.S., Djordjević, S., Butler, D., Mark, O., 2015. Urban flood impact assessment: A state-of-the-art review. Urban Water J. 12, 14-29.

https://doi.org/10.1080/1573062X.2013.857421

Haynes, P., Hehl-Lange, S., Lange, E., 2018. Mobile Augmented Reality for Flood Visualisation. Environ. Model. Softw. 109, 380-389. https://doi.org/10.1016/j.envsoft.2018.05.012

Hlodversdottir, A.O., Bjornsson, B., Andradottir, H.O., Eliasson, J., Crochet, P., 2015. Assessment of flood hazard in a combined sewer system in Reykjavik city centre. Water Sci. Technol. 71, 1471-1477. https://doi.org/10.2166/wst.2015.119

Holmgren, P., 1994. Multiple flow direction algorithms for runoff modelling in grid based elevation models: An empirical evaluation. Hydrol. Process. 8, 327-334. https://doi.org/10.1002/hyp.3360080405

Huong, H.T.L., Pathirana, A., 2011. Urbanization and climate change impacts on future urban flood risk in Can Tho city, Vietnam. Hydrol. Earth Syst. Sci. Discuss. 8, 10781-10824. https://doi.org/10.5194/hessd-8-10781-2011

Jafarzadegan, K., Merwade, V., 2019. Probabilistic floodplain mapping using HAND-based statistical approach. Geomorphology 324, 48-61. https://doi.org/10.1016/j.geomorph.2018.09.024

Jones, R., 2002. Algorithms for using a DEM for mapping catchment areas of stream sediment samples. Comput. Geosci. 28, 1051-1060. https://doi.org/10.1016/S0098-3004(02)00022-5

Keane, S., Kesler, C., Zheng, X., 2016. HAND Flood Mapping through the Tethys Platform Google Scholar. Natl. WATER Cent. Innov. Progr. SUMMER Inst. Rep. 91.

Kreibich, H., Di Baldassarre, G., Vorogushyn, S., Aerts, J.C.J.H., Apel, H., Aronica, G.T., Arnbjerg-Nielsen, K., Bouwer, L.M., Bubeck, P., Caloiero, T., Chinh, D.T., Cortès, M., 
Gain, A.K., Giampá, V., Kuhlicke, C., Kundzewicz, Z.W., Llasat, M.C., Mård, J., Matczak, P., Mazzoleni, M., Molinari, D., Dung, N. V., Petrucci, O., Schröter, K., Slager, K.,

Thieken, A.H., Ward, P.J., Merz, B., 2017. Adaptation to flood risk: Results of international paired flood event studies. Earth’s Futur. 5, 953-965.

https://doi.org/10.1002/2017EF000606

Kreibich, H., Thieken, A.H., Petrow, T., Müller, M., Merz, B., 2005. Flood loss reduction of private households due to building precautionary measures - lessons learned from the Elbe flood in August 2002. Nat. Hazards Earth Syst. Sci. 5, 117-126.

https://doi.org/10.5194/nhess-5-117-2005

Landis, J.R., Koch, G.G., 1977. The Measurement of Observer Agreement for Categorical Data. Biometrics 33, 159. https://doi.org/10.2307/2529310

Lhomme, J., Sayers, P., Gouldby, B., Wills, M., Mulet-Marti, J., 2008. Recent development and application of a rapid flood spreading method, in: Flood Risk Management: Research and Practice. pp. 15-24. https://doi.org/10.1201/9780203883020.ch2

Lindsay, J.B., Creed, I.F., 2005. Removal of artifact depressions from digital elevation models: Towards a minimum impact approach. Hydrol. Process. 19, 3113-3126. https://doi.org/10.1002/hyp.5835

Liu, Y.Y., Maidment, D.R., Tarboton, D.G., Zheng, X., Wang, S., 2018. A CyberGIS Integration and Computation Framework for High-Resolution Continental-Scale Flood Inundation Mapping. JAWRA J. Am. Water Resour. Assoc. 54, 770-784. https://doi.org/10.1111/17521688.12660

Liu, Y.Y., Maidment, D.R., Tarboton, D.G., Zheng, X., Yildirim, A., Sazib, N.S., Wang, S., 2016. A CyberGIS Approach to Generating High-resolution Height Above Nearest Drainage (HAND) Raster for National Flood Mapping. Third Int. Conf. CyberGIS Geospatial Data Sci. 1-5. https://doi.org/10.13140/RG.2.2.24234.41925/1

Loi, N.K., Liem, N.D., Tu, L.H., Hong, N.T., Truong, C.D., Tram, V.N.Q., Nhat, T.T., Anh, T.N., Jeong, J., 2019. Automated procedure of real-time flood forecasting in Vu Gia - Thu Bon river basin, Vietnam by integrating SWAT and HEC-RAS models. J. Water Clim. Chang. 10, 535-545. https://doi.org/10.2166/wcc.2018.015

López-Vicente, M., Álvarez, S., 2018. Influence of DEM resolution on modelling hydrological connectivity in a complex agricultural catchment with woody crops. Earth Surf. Process. Landforms 43, 1403-1415. https://doi.org/10.1002/esp.4321

Luke, A., Sanders, B.F., Goodrich, K.A., Feldman, D.L., Boudreau, D., Eguiarte, A., Serrano, K., Reyes, A., Schubert, J.E., Aghakouchak, A., Basolo, V., Matthew, R.A., 2018. Going beyond the flood insurance rate map: Insights from flood hazard map co-production. Nat. Hazards Earth Syst. Sci. 18, 1097-1120. https://doi.org/10.5194/nhess-18-1097-2018

Mahmood, A., 2018. Flood Hazard Mapping in Integrated Flood Risk Management: Importance and Problems Associated to Pakistan. SSRN Electron. J.

https://doi.org/10.2139/ssrn.3057194 
Mahmoud, S.H., Gan, T.Y., 2018. Urbanization and climate change implications in flood risk management: Developing an efficient decision support system for flood susceptibility mapping. Sci. Total Environ. 636, 152-167. https://doi.org/10.1016/j.scitotenv.2018.04.282

Maidment, D.R., 2017. Conceptual Framework for the National Flood Interoperability Experiment. J. Am. Water Resour. Assoc. 53, 245-257. https://doi.org/10.1111/17521688.12474

Mark, D.M., 1984. Automated detection of drainage networks from digital elevation models. Cartographica 21, 168-178. https://doi.org/10.3138/10LM-4435-6310-251R

Martz, L.W., Garbrecht, J., 1998. The treatment of flat areas and depressions in automated drainage analysis of raster digital elevation models. Hydrol. Process. 12, 843-855. https://doi.org/10.1002/(SICI)1099-1085(199805)12:6<843::AID-HYP658>3.0.CO;2-R

McGrath, H., Bourgon, J.F., Proulx-Bourque, J.S., Nastev, M., Abo El Ezz, A., 2018. A comparison of simplified conceptual models for rapid web-based flood inundation mapping. Nat. Hazards 93, 905-920. https://doi.org/10.1007/s11069-018-3331-y

Morris, J., Beedell, J., Hess, T.M., 2016. Mobilising flood risk management services from rural land: Principles and practice. J. Flood Risk Manag. 9, 50-68. https://doi.org/10.1111/jfr3.12110

Munoth, P., Goyal, R., 2019. Effects of DEM Source, Spatial Resolution and Drainage Area Threshold Values on Hydrological Modeling. Water Resour. Manag. 33, 3303-3319. https://doi.org/10.1007/s11269-019-02303-X

Nobre, A.D., Cuartas, L.A., Hodnett, M., Rennó, C.D., Rodrigues, G., Silveira, A., Waterloo, M., Saleska, S., 2011. Height Above the Nearest Drainage - a hydrologically relevant new terrain model. J. Hydrol. 404, 13-29. https://doi.org/10.1016/j.jhydrol.2011.03.051

Nobre, A.D., Cuartas, L.A., Momo, M.R., Severo, D.L., Pinheiro, A., Nobre, C.A., 2016. HAND contour: A new proxy predictor of inundation extent. Hydrol. Process. 30, 320-333. https://doi.org/10.1002/hyp.10581

Provost, F., 1998. Glossary of Terms Special Issue on Applications of Machine Learning and the Knowledge Discovery Process. Mach. Learn. 30, 271-274.

Quinn, P., Beven, K., Chevallier, P., Planchon, O., 1991. The prediction of hillslope flow paths for distributed hydrological modelling using digital terrain models. Hydrol. Process. 5, 5979. https://doi.org/10.1002/hyp.3360050106

Rennó, C.D., Nobre, A.D., Cuartas, L.A., Soares, J.V., Hodnett, M.G., Tomasella, J., Waterloo, M.J., 2008. HAND, a new terrain descriptor using SRTM-DEM: Mapping terra-firme rainforest environments in Amazonia. Remote Sens. Environ. 112, 3469-3481. https://doi.org/10.1016/j.rse.2008.03.018

Rieger, W., 1998. A phenomenon-based approach to upslope contributing area and depressions in DEMs. Hydrol. Process. 12, 857-872. https://doi.org/10.1002/(SICI)10991085(199805)12:6<857::AID-HYP659>3.0.CO;2-B 
Sanders, B.F., Schubert, J.E., 2019. PRIMo: Parallel raster inundation model. Adv. Water Resour. 126, 79-95. https://doi.org/10.1016/j.advwatres.2019.02.007

Sayama, T., Tatebe, Y., Iwami, Y., Tanaka, S., 2015. Hydrologic sensitivity of flood runoff and inundation: 2011 Thailand floods in the Chao Phraya River basin. Nat. Hazards Earth Syst. Sci. 15, 1617-1630. https://doi.org/10.5194/nhess-15-1617-2015

Sermet, Y., Demir, I., 2019a. Flood action VR: A virtual reality framework for disaster awareness and emergency response training, in: ACM SIGGRAPH 2019 Posters, SIGGRAPH 2019. Association for Computing Machinery, Inc, New York, NY, USA, pp. 1-2. https://doi.org/10.1145/3306214.3338550

Sermet, Y., Demir, I., 2019b. Towards an information centric flood ontology for information management and communication. Earth Sci. Informatics 12, 541-551. https://doi.org/10.1007/s12145-019-00398-9

Sermet, Y., Demir, I., 2018. An intelligent system on knowledge generation and communication about flooding. Environ. Model. Softw. 108, 51-60. https://doi.org/10.1016/j.envsoft.2018.06.003

Sermet, Y., Demir, I., Muste, M., 2020. A serious gaming framework for decision support on hydrological hazards. Sci. Total Environ. 728, 138895. https://doi.org/10.1016/j.scitotenv.2020.138895

Sermet, Y., Villanueva, P., Sit, M.A., Demir, I., 2019. Crowdsourced approaches for stage measurements at ungauged locations using smartphones. Hydrol. Sci. J. 65, 813-822. https://doi.org/10.1080/02626667.2019.1659508

Short Gianotti, A.G., Warner, B., Milman, A., 2018. Flood concerns and impacts on rural landowners: An empirical study of the Deerfield watershed, MA (USA). Environ. Sci. Policy 79, 94-102. https://doi.org/10.1016/j.envsci.2017.10.007

Sit, M., Demir, I., 2019. Decentralized Flood Forecasting Using Deep Neural Networks.

Sit, M., Sermet, Y., Demir, I., 2019. Optimized watershed delineation library for server-side and client-side web applications. Open Geospatial Data, Softw. Stand. 4. https://doi.org/10.1186/s40965-019-0068-9

Sit, M.A., Koylu, C., Demir, I., 2019. Identifying disaster-related tweets and their semantic, spatial and temporal context using deep learning, natural language processing and spatial analysis: a case study of Hurricane Irma. Int. J. Digit. Earth 12, 1205-1229. https://doi.org/10.1080/17538947.2018.1563219

Speckhann, G.A., Borges Chaffe, P.L., Fabris Goerl, R., Abreu, J.J. de, Altamirano Flores, J.A., 2018. Flood hazard mapping in Southern Brazil: a combination of flow frequency analysis and the HAND model. Hydrol. Sci. J. 63, 87-100. https://doi.org/10.1080/02626667.2017.1409896

Tam, T.H., Abd Rahman, M.Z., Harun, S., Hanapi, M.N., Kaoje, I.U., 2019. Application of satellite rainfall products for flood inundation modelling in Kelantan River Basin, Malaysia. Hydrology 6, 95. https://doi.org/10.3390/HYDROLOGY6040095 
Tarboton, D.G., 1997. A new method for the determination of flow directions and upslope areas in grid digital elevation models. Water Resour. Res. 33, 309-319.

https://doi.org/10.1029/96WR03137

Teng, J., Jakeman, A.J., Vaze, J., Croke, B.F.W., Dutta, D., Kim, S., 2017. Flood inundation modelling: A review of methods, recent advances and uncertainty analysis. Environ. Model. Softw. https://doi.org/10.1016/j.envsoft.2017.01.006

Teng, J., Vaze, J., Dutta, D., Marvanek, S., 2015. Rapid Inundation Modelling in Large Floodplains Using LiDAR DEM. Water Resour. Manag. 29, 2619-2636. https://doi.org/10.1007/s11269-015-0960-8

UIHILab, 2020. Interactive and Real-time Flood Inundation Mapping on Client-Side Web Systems. UIHILab-Hydroinformatics Lab Univ. Iowa. https://hydroinformatics.uiowa.edu/projects/projects_hand.php (accessed 4.23.20).

Weber, L.J., Muste, M., Bradley, A.A., Amado, A.A., Demir, I., Drake, C.W., Krajewski, W.F., Loeser, T.J., Politano, M.S., Shea, B.R., Thomas, N.W., 2018. The Iowa Watersheds Project: Iowa's prototype for engaging communities and professionals in watershed hazard mitigation. Int. J. River Basin Manag. 16, 315-328.

https://doi.org/10.1080/15715124.2017.1387127

Wilks, D., 2011. Statistical Methods in the Atmospheric Sciences - Daniel S. Wilks. (accessed 4.24.20).

Xiang, Z., Yan, J., Demir, I., 2020. A Rainfall-Runoff Model With LSTM-Based Sequence-toSequence Learning. Water Resour. Res. 56. https://doi.org/10.1029/2019WR025326@10.1002/(ISSN)1944-7973.MACHINELEARN

Xu, H., Windsor, M., Muste, M., Demir, I., 2020. A web-based decision support system for collaborative mitigation of multiple water-related hazards using serious gaming. J. Environ. Manage. 255, 109887. https://doi.org/10.1016/j.jenvman.2019.109887

Yan, F., 2019. Floods and Culture. Springer, Cham. https://doi.org/10.1007/978-3-319-901732_2

Yazdanfar, Z., Sharma, A., 2015. Urban drainage system planning and design - Challenges with climate change and urbanization: A review. Water Sci. Technol. https://doi.org/10.2166/wst.2015.207

Yildirim, E., Demir, I., 2019. An integrated web framework for HAZUS-MH flood loss estimation analysis. Nat. Hazards 99, 275-286. https://doi.org/10.1007/s11069-019-03738-6

Zheng, X., Tarboton, D.G., Maidment, D.R., Liu, Y.Y., Passalacqua, P., 2018. River Channel Geometry and Rating Curve Estimation Using Height above the Nearest Drainage. J. Am. Water Resour. Assoc. 54, 785-806. https://doi.org/10.1111/1752-1688.12661

Zhou, Q., Leng, G., Su, J., Ren, Y., 2019. Comparison of urbanization and climate change impacts on urban flood volumes: Importance of urban planning and drainage adaptation. Sci. Total Environ. 658, 24-33. https://doi.org/10.1016/j.scitotenv.2018.12.184 